\title{
Durability analysis of underground structures based on various creep models of the enclosing salt rock massif
}

\author{
Mikhail Zhuravkov ${ }^{1}$, Sergey Hvesenya ${ }^{1}$, and Siarhei Lapatsin ${ }^{1 *}$ \\ ${ }^{1}$ Belarusian State University, Department of Theoretical and Applied Mechanics, 4 Nezavisimosti Ave., \\ 220030 Minsk, Belarus
}

\begin{abstract}
The results of the durability analysis of a complex underground structure and surrounding multilayered rock massif are presented. The research is conducted based on an applied stress-strain state problem for a salt rock massif in the vicinity of an underground cavity of a large cross-section which is in conjunction with a mine shaft. The main aim of the research is to perform a comparative analysis of various mathematical models of the creep process. The problem is solved using finite element method to achieve this goal. Regularity in the development of deformation processes of the enclosing rock massif is established as a result of the study. According to this regularity, both primary creep and primary-secondary creep models show that the main increase of creep deformations occurs during a short initial time period after which creep strain rate decreases sharply.
\end{abstract}

\section{Introduction}

Durability estimation of underground structures is one of the most common and at the same time challenging problems of the mining industry. As examples of ongoing interest to the problem, we mention recent publications and references therein [1 -3$]$.

It is well known that all rocks have creep property [4, 5]. It means that all of them are deforming permanently under the influence of persistent mechanical stresses. Creep is a crucial factor for long-term stability analysis of underground structures such as capital and preparatory excavations, pillars, ceilings, and other rock outcrops. Here we refer to work [6], which is establishing a consensus in creep modelling within geotechnical engineering and summarizes creep data for some geomaterials.

Durability analysis of rock massifs in the vicinity of underground structures is essentially determined by choice of rock mass creep model. Mathematical model of rheological behavior of rock massif should be chosen reasonably based on laws and features of the physical process under consideration. Studies [7, 8] are the examples of modern approaches to mathematical modelling of rheological behavior of rocks. Work [9], in turn, demonstrates the effect of temperature on the time-dependent behavior of geomaterials.

\footnotetext{
* Corresponding author: lopatinsn@tut.by
} 
An important feature of the rheological processes is that deformation at any time point depends on the previous history of loading. This property of real materials is called heredity [4]. In this regard, the theory of hereditary creep is widely used in rock mechanics along with technical theories (aging theory, hardening theory) $[10,11]$. This theory fits the experimental data $[12-14]$.

The equation of Boltzmann-Volterra (hereditary creep equation) in case of a uniaxial stress state can be written as [15]:

$$
\varepsilon(t)=\frac{\sigma(t)}{E}+\frac{1}{E} \int_{0}^{t} K(t-\tau) \sigma(\tau) d \tau,
$$

where $\sigma(t), \varepsilon(t)$ are stress and strain at time $t ; \tau$ is a time moment before $t ; E$ is elastic modulus of material; $K(t-\tau)$ is creep kernel (or influence function).

Creep equation (2) can be obtained from (1) in case of $\sigma(t)=\sigma_{k}=$ const:

$$
\varepsilon(t)=\frac{\sigma_{k}}{E}\left[1+\int_{0}^{t} K(\tau) d \tau\right]
$$

After differentiation of (2) with respect to $t$ we obtain:

$$
K(t)=\frac{E}{\sigma_{k}} \frac{d \varepsilon(t)}{d t}
$$

Therefore, function $K(t)$ is proportional to the creep rate function.

Hereditary creep equation can in turn be written as follows:

$$
\varepsilon(t)=\int_{0}^{t} P(t-\tau) d \sigma(\tau),
$$

where $(t)$ is malleability or creep function which can be expressed via creep rate function $K(t)$ in the following form [15]:

$$
P(0)=E^{-1}, P^{\prime}(t)=E^{-1} K(t),
$$

$$
P(t)=\frac{\varepsilon(t)}{\sigma_{k}} P(t) \text { while } \sigma(t)=\sigma_{k}=\text { const. }
$$

The largest value of $\sigma_{k}$ for which malleability curves $P(t)$ coincide or fit into a narrow bundle of curves for all values of $\sigma_{k}$ and $t$ is called a bound of deformation linearity area. Linear equations (1) and (4) can be applied in this area only.

The deformation of most rocks in the linear area corresponds to equations (1) and (4) with a creep kernel in the form of a power function (Abelian kernel) $[12,16]$ :

$$
K(t, \tau)=\delta(t-\tau)^{-\alpha},
$$

where $\delta$ and $\alpha$ are creep parameters, which are derived as a result of experimental data processing.

Creep kernel (6) is widely used within rock mechanics for a number of reasons. First of all, the algorithm of finding parameters $\alpha$ and $\delta$ is developed quite well [4, 17]. A number of experimental studies show that the dimensionless parameter $\alpha$ is close to 0.7 regardless of the rock type $[12,16]$. Therefore, the main difficulty is to define the value of the parameter $\delta$ which characterizes the creep rate. The value of $\delta$ shows the activity of rheological processes in various rocks. In addition, the experimental data on rocks creep is characterized by a very significant dispersion [13, 16, 17]. Therefore, a decrease of parameters number of the mathematical model is highly desirable. 
However, the approximation of the creep kernel by the Abelian kernel has a significant disadvantage. The Abelian kernel does not allow to describe a limited creep of rocks under pressure which is less than the linearity limit. In addition, the numerical values of the parameters $\alpha$ and $\delta$ are highly dependent on the time interval, for which they are derived. This is very important because the period of creep experiments on rock samples usually does not exceed a year. Also, the methods of the rocks rheological parameters assessing under natural conditions do not allow to eliminate the influence of various mining and geological factors.

The results of the studies on the approximation of the creep kernel of sylvinite samples on the example of the Verkhnekamskoe deposit of potassium salts are presented in [13]. Abelian kernel, Koltunov's kernel and spectral kernel were used for the approximation [18]. Creep function or malleability function of the spectral kernel can be written as [13]:

$$
P(t)=C_{0}+\sum_{k=1}^{n} C_{k} e^{-\alpha_{k} t}
$$

where $C_{0}, C_{1}, \ldots, C_{n}$ and $\alpha_{0}, \alpha_{1}, \ldots, \alpha_{n}$ are approximation parameters.

A comparison of the creep curves for all three types of creep kernels with the experimental data showed that used creep functions adequately predict the creep of the samples [13]. However, there are some deviations from the experimental curve [13]. The Abelian kernel has shown the largest deviation from the experimental data, while the spectral kernel has shown the most accurate prediction [13]. In addition, studies show that the Koltunov's and spectral kernels allow to describe a limited creep over ten years. The Abelian kernel predicts the deformation that does not decay in time.

Thus, the Abelian creep kernel for rocks with significant rheological properties (such as rock salt) gives an estimation of the creep deformations of pillars with a very large margin [16]. In assessing the sustainability of capital excavations, such a large reserve makes sense, because it compensates some mining or technical factors.

Earlier some authors [19] proposed the spectral type kernel to describe the uniaxial creep of salt rocks. Due to the development of numerical methods and computing systems, this idea can be revised.

In general, numerical methods are very popular in geomechanics nowadays. For example recent works [20-23] perform numerical analysis of different geotechnical problems. Authors of [24], in turn, use numerical methods to check and refine previous analytical solutions of the problem.

Therefore, the problem of comparison of various mathematical models of the creep process remains a pressing issue. This paper performs such a comparison using real experimental data. The consideration below is a real applied problem, so the results may be used as a representation of how various creep models predict massif deformations in natural conditions.

\section{Statement of the problem}

As noted earlier, the main aim of the consideration below is to compare stress-strain states of a rock mass in the vicinity of underground structure using various mathematical models of the creep process.

The research is conducted based on an applied problem of determination of the stressstrain state of a rock-salt massif around an underground cavity of a large cross-section (chamber), which is in conjunction with a shaft (Fig. 1). 

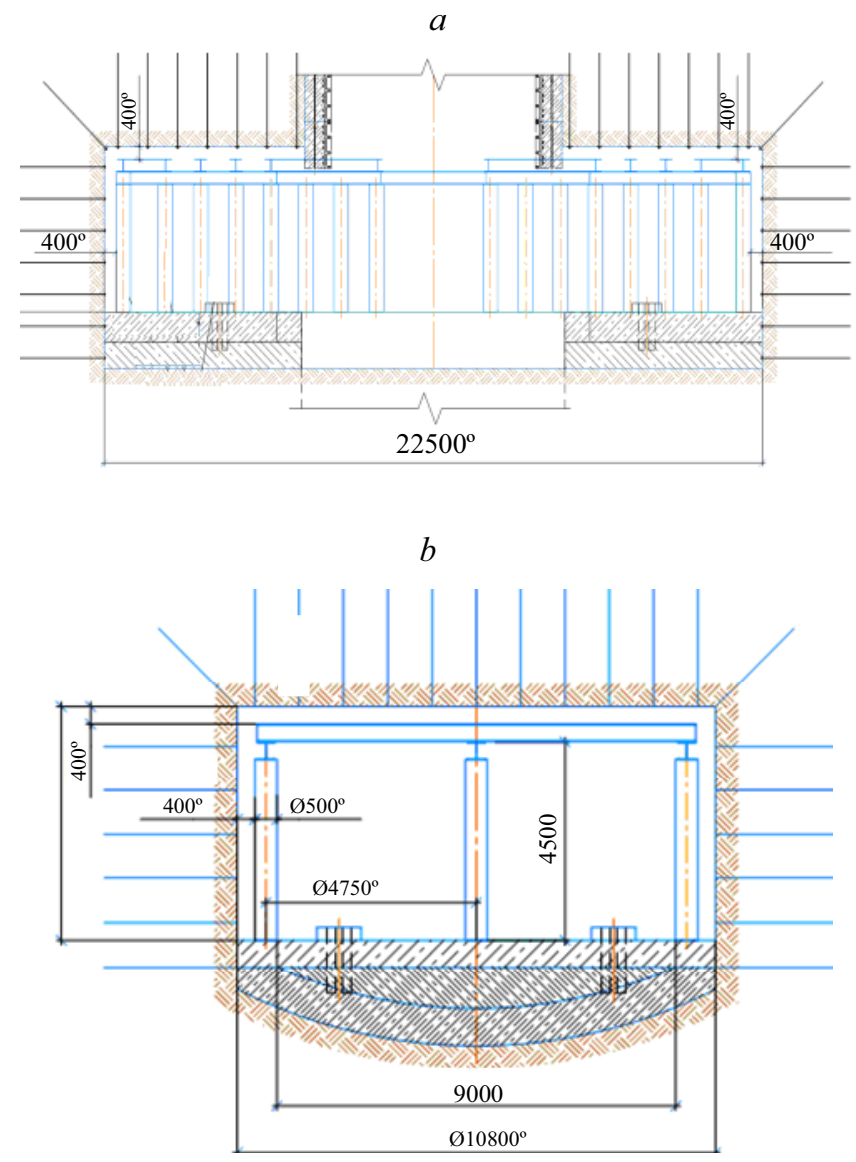

$c$

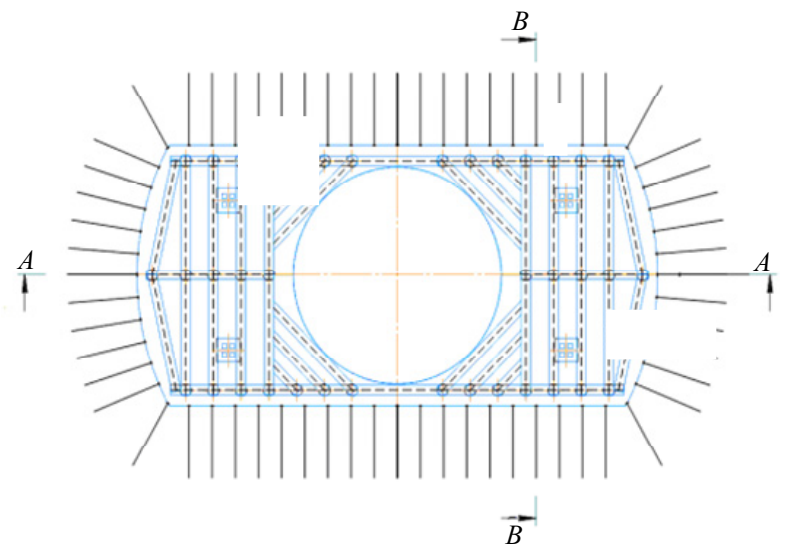

Fig. 1. Underground chamber: $a$ - longitudinal section; $b$ - transverse section; $c$ - top view.

From the standpoint of long-term stability, pillar elements are the most dangerous parts of the chamber contour. Excessive displacements of the rock mass on the sides of the chamber can cause zones of discontinuity/destruction in the surrounding massif, which, in turn, can cause fatal influence on the structure of the chamber in general. 


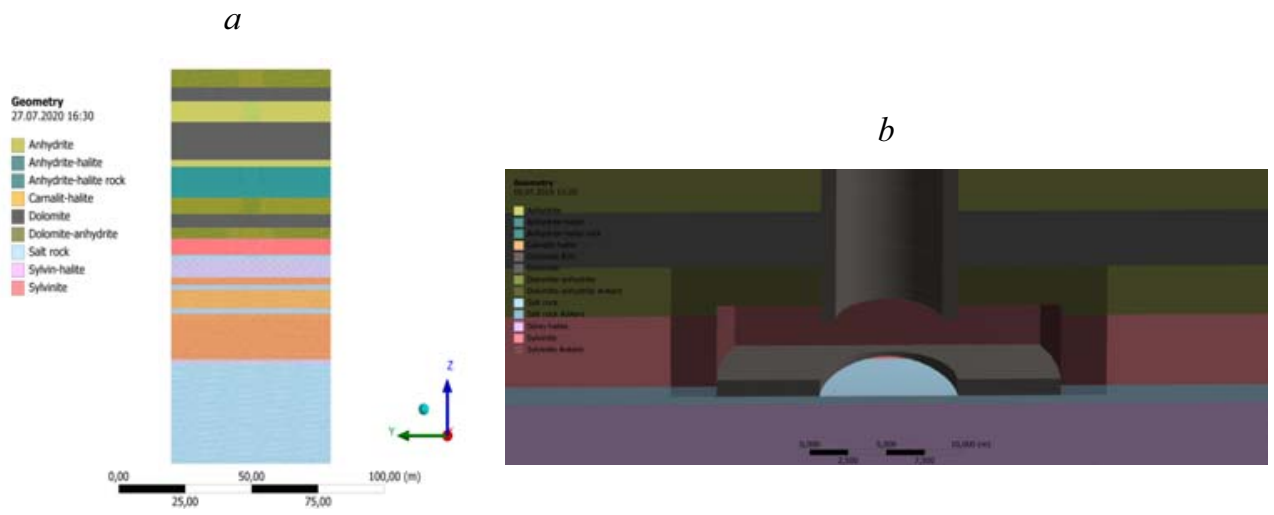

Fig. 2. 3D model of the problem: $a$-rock massif cross-section at initial stage; $b$-cross section of the underground structure.

The chamber is located in a multilayered massif at depths of $1095-1102 \mathrm{~m}$. Dolomiteanhydrite, sylvinite and salt rock bed in the interval under consideration (Fig. 2).

\section{Creep models and material properties}

Creep model of salt rocks, which uses a nonlinear version of the hereditary creep theory is offered by Konstantinova in work [15]:

$$
\varepsilon(t)=\frac{1}{E}\left(\sigma(\tau)+\int_{0}^{t} K(t-\tau, \sigma(\tau)) \sigma(\tau) d \tau\right),
$$

where $K(t-\tau, \sigma(\tau))$ can be expressed as [15]:

$$
K(t-\tau, \sigma(\tau))=L(t-\tau) f(\sigma(\tau))
$$

where $f(\sigma(\tau))$ is nonlinear function of stress, $L(t-\tau)$ is creep kernel.

The most common form of $K(t-\tau, \sigma(\tau))$ is the next dependence of creep strain rate $\dot{\varepsilon}$ on equivalent stress $\sigma_{\text {eqv }}$ :

$$
\dot{\varepsilon}=C_{1} \sigma_{e q \nu}{ }^{c_{2}} t^{c_{3}}
$$

Using (10), one can obtain the dependence of creep deformations $\mathcal{E}$ on the equivalent stress $\sigma_{e q v}$ in the following form by integrating this expression over time:

$$
\varepsilon=\frac{C_{1} \sigma_{e q v}{ }^{c_{2}} t^{c_{3}}}{c_{3}}+\varepsilon_{0} .
$$

However, for a more correct description of creep deformations for nonstandard engineering problems, a larger number of components is required.

As is well known, there are three general intervals on the creep curve. On the first interval, the creep strain rate is relatively high, but decreases monotonically, starting from some high value. This interval is called an interval of unsteady or primary creep. The second interval is almost linear. The interval is called an interval of steady or secondary creep. Creep strain rate is almost constant at this interval. Finally, one can observe a predestruction interval, where the creep strain rate monotonically increases [10]. 
Regarding this, one can also use the following dependence as a function $K(t-\tau, \sigma(\tau))$ :

$$
\varepsilon=C_{1} \sigma_{e q v}{ }^{c_{2}} t^{c_{3}}+C_{4} \sigma_{e q v}{ }^{c_{5}} t+\varepsilon_{0} .
$$

The peculiarity of expression (9) is that it takes into account both primary and secondary creep.

Material properties used for the calculations according to expressions (10), (11) and (12) are presented in the tables below [25].

Table 1. Elastic properties of rocks.

\begin{tabular}{|c|c|c|c|c|c|c|}
\hline Rock & $\begin{array}{c}\text { Young's } \\
\text { modulus, } \\
\text { MPa }\end{array}$ & $\begin{array}{c}\text { Poisson's } \\
\text { ratio }\end{array}$ & $\begin{array}{c}\text { Ultimate } \\
\text { tensile } \\
\text { strength } \\
\text { (mom), MPa }\end{array}$ & $\begin{array}{c}\text { Ultimate } \\
\text { compressive } \\
\text { strength } \\
\text { (mom), MPa }\end{array}$ & $\begin{array}{c}\text { Ultimate } \\
\text { tensile } \\
\text { strength } \\
\text { (long), MPa }\end{array}$ & $\begin{array}{c}\text { Ultimate } \\
\text { compressive } \\
\text { strength } \\
\text { (long), MPa }\end{array}$ \\
\hline Dolomite-anhydrite & 61552 & 0.357 & 5.9 & 95 & 2.95 & 47.5 \\
\hline Sylvinite & 20614 & 0.222 & 1 & 37.2 & 0.4 & 14.6 \\
\hline Salt rock & 22797 & 0.357 & 1 & 22.8 & 0.6 & 15.1 \\
\hline
\end{tabular}

Table 2. Coulomb-Mohr parameters of rocks.

\begin{tabular}{|c|c|c|c|c|c|}
\hline Rock & $\begin{array}{c}\text { Initial } \\
\text { cohesion, } \\
\mathrm{MPa}\end{array}$ & $\begin{array}{c}\text { Initial inner } \\
\text { friction angle, } \\
\text { degree }\end{array}$ & $\begin{array}{c}\text { Residual } \\
\text { cohesion, } \\
\mathrm{MPa}\end{array}$ & $\begin{array}{c}\text { Residual inner } \\
\text { friction angle, } \\
\text { degree }\end{array}$ & $\begin{array}{c}\text { Dilatancy angle, } \\
\text { degree }\end{array}$ \\
\hline Dolomite-anhydrite & 5.2 & 41 & 3.6 & 33 & 3 \\
\hline Sylvinite & 5.1 & 70 & 3.4 & 50 & 3 \\
\hline Salt rock & 3.8 & 60 & 3 & 51 & 3 \\
\hline
\end{tabular}

Table 3. Creep constants for model (10).

\begin{tabular}{|c|c|c|c|}
\hline Rock & Creep constant $C_{1}$ & Creep constant $C_{2}$ & Creep constant $C_{3}$ \\
\hline Dolomite-anhydrite & $1 \cdot 10^{-36}$ & 4.2 & -0.7 \\
\hline Sylvinite & $1 \cdot 10^{-36}$ & 4.2 & -0.7 \\
\hline Salt rock & $1 \cdot 10^{-36}$ & 4.2 & -0.68 \\
\hline
\end{tabular}

Table 4. Creep constants for model (11).

\begin{tabular}{|c|c|c|c|}
\hline Rock & Creep constant $C_{1}$ & Creep constant $C_{2}$ & Creep constant $C_{3}$ \\
\hline Dolomite-anhydrite & $3.125 \cdot 10^{-37}$ & 4.2 & 0.3 \\
\hline Sylvinite & $3.33 \cdot 10^{-37}$ & 4.2 & 0.3 \\
\hline Salt rock & $3.125 \cdot 10^{-37}$ & 4.2 & 0.32 \\
\hline
\end{tabular}

Table 5. Creep constants for model (12).

\begin{tabular}{|c|c|c|c|c|c|}
\hline Rock & $\begin{array}{c}\text { Creep constant } \\
C_{1}\end{array}$ & $\begin{array}{c}\text { Creep constant } \\
C_{2}\end{array}$ & $\begin{array}{c}\text { Creep constant } \\
C_{3}\end{array}$ & $\begin{array}{c}\text { Creep constant } \\
C_{4}\end{array}$ & $\begin{array}{c}\text { Creep constant } \\
C_{5}\end{array}$ \\
\hline Dolomite-anhydrite & $2.5 \cdot 10^{-12}$ & 1.3 & -0.8 & $5.1 \cdot 10^{-38}$ & 4.2 \\
\hline Sylvinite & $2.5 \cdot 10^{-12}$ & 1.3 & -0.8 & $5.1 \cdot 10^{-38}$ & 4.2 \\
\hline Salt rock & $2.5 \cdot 10^{-12}$ & 1.3 & -0.8 & $5.1 \cdot 10^{-38}$ & 4.2 \\
\hline
\end{tabular}

\section{Finite-element model of the problem}

The solution of the problem is performed by a numerical method based on finite element difference schemes in three-dimensional setting. Coulomb-Mohr elastic-plastic model is used as basic mechanical model describing behavior of rock massifs.

According to Fig. 1, an iron grid with $3 \mathrm{~m}$ arch support on the walls and roof of the chamber are used as safety measures in the interval of dolomite-anhydrite and sylvinite. 
Concrete lining together with reinforced concrete foundation is in the interval of rock salt.

Here we assume that arch support increases Young's modulus and ultimate compressive strength of rocks by $20 \%$ [12].

The own weight of both considered and overlaying rock massif is taken into account in all calculations.

The solution of the problem is divided into the following steps:

1) Calculation of the initial stress-strain state of the rock massif.

2) Calculation of the stress-strain state of the rock massif in total stresses and additional displacements [10] in the area of the chamber. The calculation is performed step by step, taking i construction stage into account.

3) Stress-strain state calculation of the system after arch support installation (in terms of total stresses and additional displacements [10]).

4) Durability calculation considering creep.

\section{Results and discussion}

Fig. 3 shows static displacements which occur due to elastic and plastic deformations during excavation works.

$a$

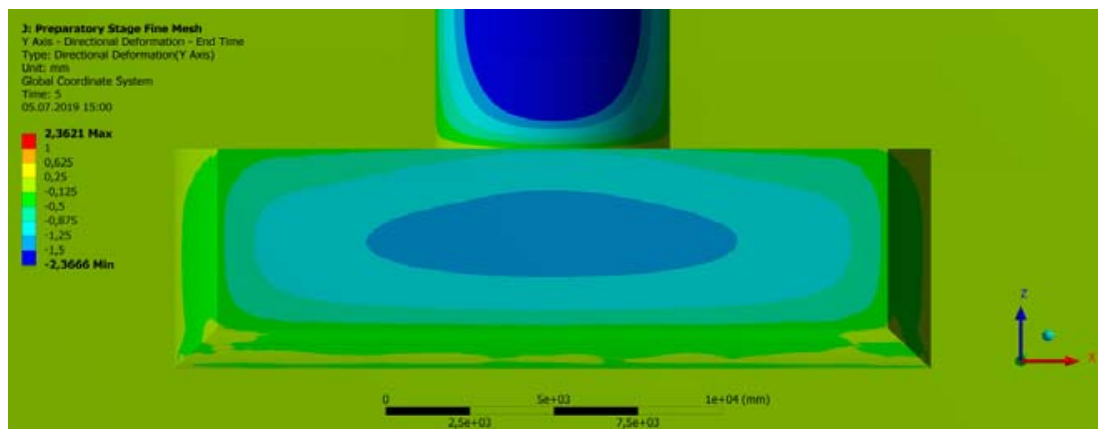

$b$

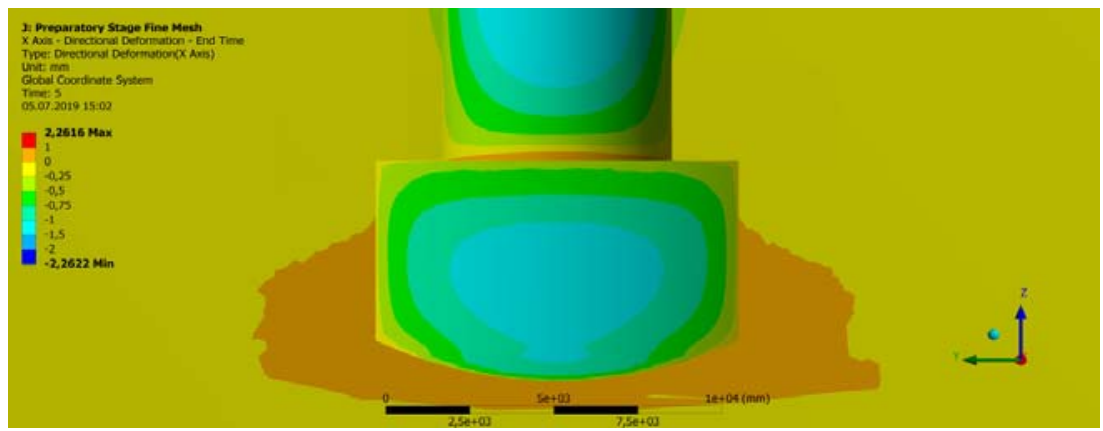

Fig. 3. Some results of static numerical calculations: $a$-displacements distribution in longitudinal section; $b$-displacements distribution in transverse section.

Further we estimate normal displacements of the rock massif. These displacements occur due to three types of deformations - elastic deformations, plastic (Coulomb-Mohr) deformations and creep deformations. Total displacements of the massifs are calculated as a sum of the following components: 


$$
\begin{aligned}
& U_{x_{\text {total }}}=U_{x_{\text {elastic }}}+U_{x_{\text {plastic }}}+U_{x_{\text {creep }}} ; \\
& U_{y_{\text {total }}}=U_{y_{\text {elastic }}}+U_{y_{\text {plastic }}}+U_{y_{\text {creep }}} ; \\
& U_{z_{\text {total }}}=U_{z_{\text {elastic }}}+U_{z_{\text {plastic }}}+U_{z_{\text {creep }}},
\end{aligned}
$$

where $U_{x}$ is maximum displacement at a short wall of the chamber; $U_{y}$ is maximum displacement at a long wall of the chamber; $U_{z}$ is maximum displacement at the roof of the chamber.

The results of the calculations are presented below (Figs. 4 and 5). The graphs bellow show the comparison of stresses and displacements obtained according to models (10), (11), (12).

$a$

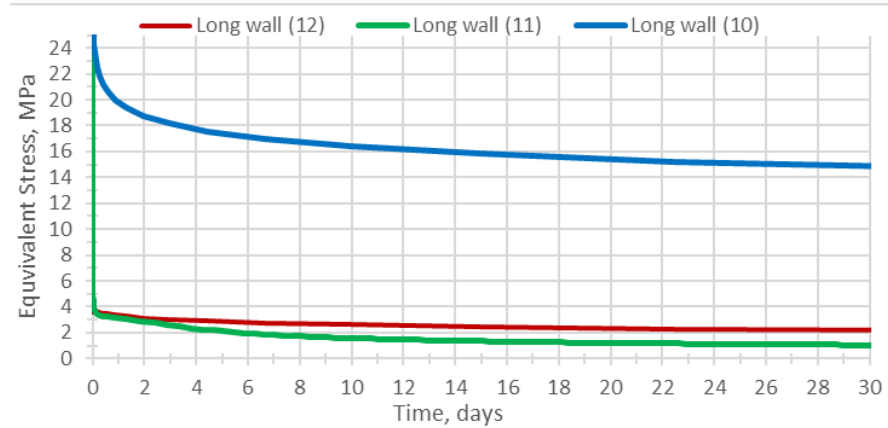

$b$

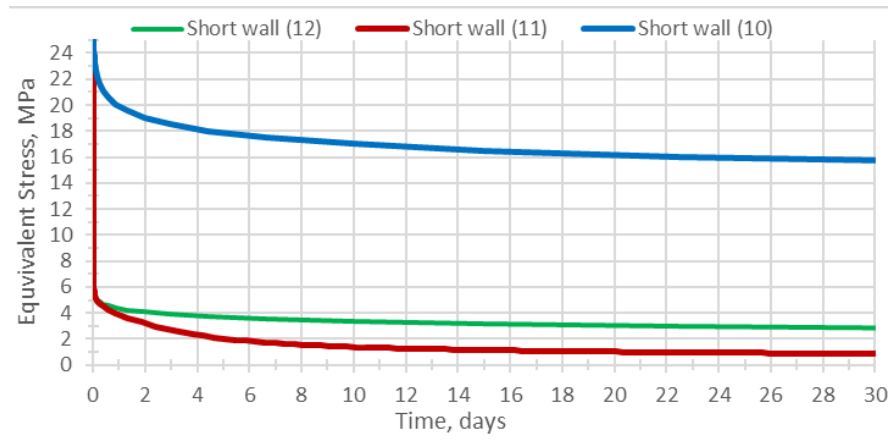

$c$

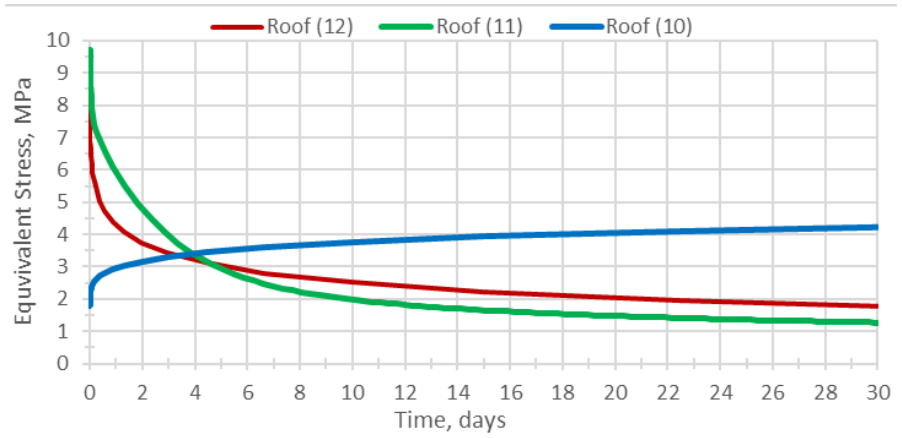

Fig. 4. Equivalent stress graphs according to various creep models: $a$ - on the long wall of the chamber; $b$ - on the short wall of the chamber; $c$ - on the roof of the chamber. 


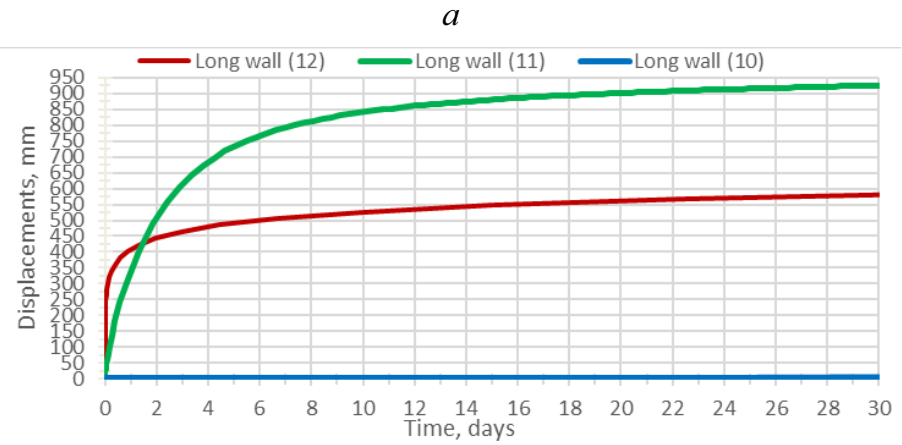

$b$

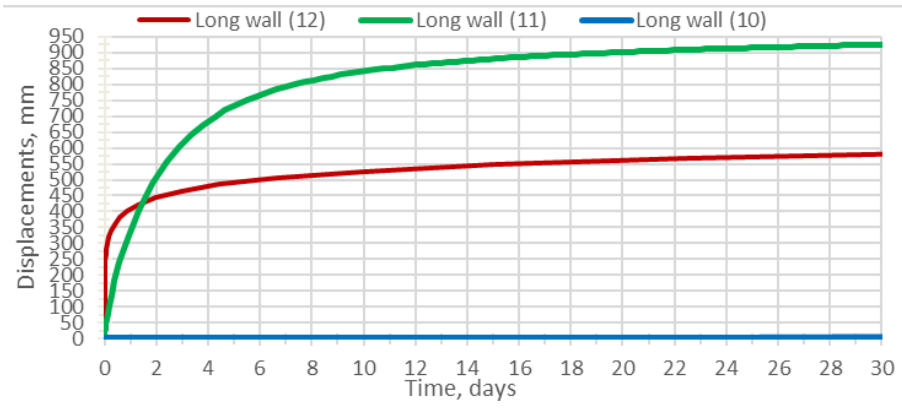

c

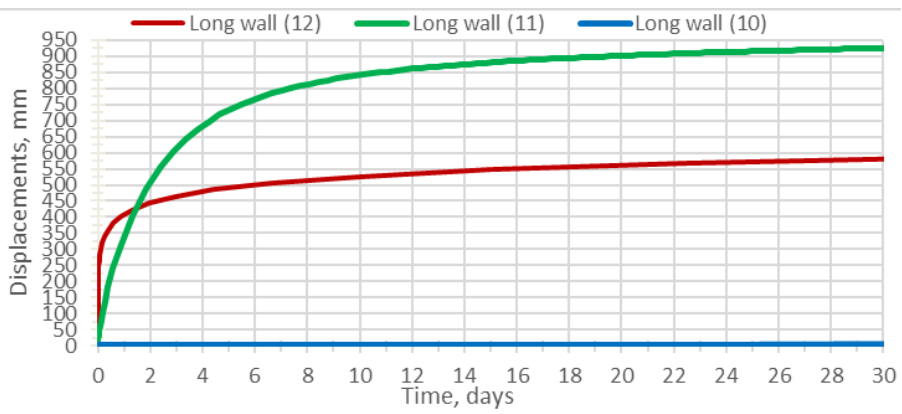

Fig. 5. Normal displacements graphs according to various creep models: $a$-on the long wall of the chamber; $b-$ on the short wall of the chamber; $c-$ on the roof of the chamber.

\section{Conclusions}

The calculations of the stress-strain state of salt rock massif in the neighborhood of the underground support beams chamber of a skip shaft are carried out within the framework of the model studies. Moreover, a comparative durability analysis of the chamber is performed using various mathematical creep models in this paper.

The results of this analysis allow us to conclude that various mathematical creep models lead to completely different distributions of stresses and strains even when the predictions are based on the same experimental data. The difference in stresses and displacements is especially noticeable when comparing models that specify creep via creep strain, which is a function of stress and time (11), (12), with a model that specifies creep via creep strain rate which is a function of stress and time (10). 
Figs. 4 and 5 establish an important regularity in the development of deformation processes. According to this regularity, both primary and primary-secondary creep models show that the main increase of creep deformations occurs in a small initial period of time, after which the strain rate decreases sharply. Authors suppose that this regularity is due to an ignorance of the scale factor during the conduction of creep experiments. The problem of the scale factor has a wide resonance in modern geomechanics. For more details one can refer to [26].

Thus, the problem of choosing a creep model for rocks that adequately describes geomechanical processes in the neighborhood of underground structures requires special studies and in-situ verification tests.

This work was conducted within the state research program "Convergence-2020" of the Republic of Belarus (State registration No. 20161712). Task No. 1.8.01.1 "Development of mathematical models and methods for solving new classes of boundary value problems of continuum mechanics as applied to current contemporary problems of science and technology".

\section{References}

1. Zeng, X., Wang, Z., Fan, J., Zhao, L., Lin, D., \& Zhao, J. (2011). Problems of durability and reinforcement measures for underground structures in China. Journal of Rock mechanics and geotechnical engineering, 3(3), 250-259. https://doi.org/10.3724/SP.J.1235.2011.00250

2. Trofimov, V. (2019). On Deformation Stability of Rock Massif. Trigger Effects in Geosystems, 407-415. https://doi.org/10.1007/978-3-030-31970-0 43

3. Alam, S., Das, S.K., \& Rao, B.H. (2019). Strength and durability characteristic of alkali activated GGBS stabilized red mud as geo-material. Construction and Building materials, (211), 932-942. https://doi.org/10.1016/j.conbuildmat.2019.03.261

4. Yerzhanov, Z., \& Bergman, E. (1977). Polzuchest' solyanykh porod. Alma-Ata: Nauka, 110.

5. Enomoto, T., Koseki, J., Tatsuoka, F., \& Sato, T. (2015). Creep failure of sands exhibiting various viscosity types and its simulation. Soils and Foundations, 55(6), 1346-1363. https://doi.org/10.1016/j.sandf.2015.10.002

6. Grimstad, G., Karstunen, M., Jostad, H.P., Sivasithamparam, N., Mehli, M., Zwanenburg, C., Haan, E., Amiri, S.A.G., Boumezerane, D., Kadivar, M., Ashfari, M.A.H., \& Roningen, J.A. (2017). Creep of geomaterials - some finding from the EU project CREEP. European Journal of Environmental and Civil Engineering, 1-16. https://doi.org/10.1080/19648189.2016.1271360

7. Yang, G.H., Jie, Y.X., \& Li, G.X. (2013). A mathematical approach to establishing constituitive models for geomaterials. Journal of Applied Mathematics, (2013), https://doi.org/10.1155/2013/739068

8. Cao, T.D., Sanavia, L., \& Schrefler, B.A. (2015). A thermo-hydro-mechanical model for multiphase geomaterials in dynamics with application to strain localization simulation. International Journal for Numerical Methods in Engineering, (107), 312-337. https://doiorg.ezproxy.keele.ac.uk/10.1002/nme.5175

9. Zhang, S., Xu, S., Teng, J., \& Xiong, Y. (2016). Effect of temperature on time-dependent behavior of geomaterials. Comptes Rendus Mecanique, 344(8), 603-611. https://doi.org/10.1016/j.crme.2016.04.005

10. Zhuravkov, M., \& Staravoitov, E. (2011). Continuum mechanics. Elasticity and plasticity theory. Minsk: BGU.

11. Bertram, A., \& Glüge, R. (2015). Solid Mechanics. https://doi.org/10.1007/978-3-319-19566-7

12. Zhuravkov, M., \& Martynenko, M. (1995). Teoreticheskie osnovy deformatsionnoy mekhaniki blochno-sloistogo massiva solyanyh porod. Minsk: Universitetskoe.

13. Konstantinova, S., Pesterin, V., \& Pesterina, I. (2007). On various types of approximation of creep curves of samples of salt rocks. Izvestiya Vyzov. Gornyy Zhurnal, (4), 92-98. 
14. Baryakh, A., Asanov, V., \& Pan'kov, I. (2008). Fiziko-mekhanicheskie svoystva solyanykh porod Verkhnekamskogo kaliynogo mestorozhdeniya. Perm': Izdatel'stvo Permskogo gosudarstvennogo universiteta.

15. Konstantinova, S., \& Aptukov, V. (2013). Nekotorye zadachi mekhaniki deformirovaniya $i$ razrusheniya solyanykh porod. Novosibirsk: Nauka.

16. Baryakh, A., Konstantinova, S., Asanov, V. (1996). Defirmirovanie solyanyh porod. Ekaterinburg: UrO RAN.

17. Kartashov, U. (1979). Prochnost' i deformiruemost' gornykh porod. Moskva: Nedra.

18. Koltunov, M. (1976). Polzuchest' i relaksatsiya. Moskva: Vysshaya shkola.

19. Gabdrahimov, I., Dedukin, M., \& Pozdeev, A. (1977). Creep and the phenomenological theory of long-term rock strength. In 5th applied problems of rock mechanics conference of the USSR (pp. 71-75).

20. Laouafa, F., Prunier, F., Daouadji, A., Al Gali, H., \& Darve, F. (2010). Stability in geomechanics, experimental and numerical analyses. Numerical and Analytical Methods in Geomechanics, (35), 112-139. https://doi-org.ezproxy.keele.ac.uk/10.1002/nag.996

21. Onate, E., \& Rojeck, J. (2004). Combination of discrete element and finite element methods for dymnamic analisys of geomechanics problems. Computer methods in Applied Mechanics and Engeneering, 193(27-29), 3087-3128. https://doi.org/10.1016/j.cma.2003.12.056

22. Mikelic, A., Wang, B., Wheeler, M. F. (2014). Numerical convergence study of iterative coupling fo couoled flow and geomechanics. Computational Geosciences, (18), 325-341. https://doi.org/10.1007/s10596-013-9393-8

23. Park, B.Y, Sobolik, S.R., \& Herrick, C.G. (2018). Geomechanical Model Calibration Using Field Measurements for a Petroleum Reserve. Rock mechanics and Rock Engineering, (51), 925-943. https://doi-org.ezproxy.keele.ac.uk/10.1007/s00603-017-1370-4

24. Sexton, B.G, McCabe, B.A. (2013). Numerical modelling of the improvements to primary and creep settlements offered by granular columns, Acta Geotechnica, (8), 447-464. https://doiorg.ezproxy.keele.ac.uk/10.1007/s11440-012-0205-4

25. Kazlouski, Y., Zhuravkov, M., \& Bogdan, S. (2019). Shaft convergence analysis in a rock mass with a spatial heterogeneous creep. In 2th International Conference "Mines of the Future" (p. 72).

26. Norel', B.K., Petrov, Yu.V., \& Selyutina, N.S. (2019). Energeticheskie $i$ vremennye kharakteristiki gornykh porod. Sankt-Peterburg: Izdatel'stvo SpbGU. 